\title{
A Converter Based on Independently Inductive Energy Injection and Free Resonance for Wireless Energy Transfer
}

\author{
Lin Chen ${ }^{1,2}$, Jianfeng Hong ${ }^{1}$, Mingjie Guan ${ }^{1}{ }^{\mathbb{D}}$, Zaifa Lin $^{1}$ and Wenxiang Chen ${ }^{1, *}$ \\ 1 Department of Instrumental and Electrical Engineering, Xiamen University, Xiamen 361005, China \\ 2 Department of Biological System Engineering, Washington State University, Pullman, WA 99164, USA \\ * Correspondence: wxchen@xmu.edu.cn; Tel.: +86-0592-218-7512
}

Received: 2 July 2019; Accepted: 5 September 2019; Published: 8 September 2019

\begin{abstract}
Strong coupling in an inductive power transfer (IPT) system will lead to difficulties in power control and loss of soft switching conditions. This paper presents an IPT system that can decouple the converter from the resonant network. In the proposed system, the energy transmission process is divided into energy injection stage and free resonance stage. In the energy injection stage, the inductor is separated from the resonance network, and the power source injects energy into the inductor independently. In the free resonance stage, the inductor is connected to the resonance network for resonating. As a benefit from the decoupling of the converter from the resonance network, the proposed IPT system is characterized by easy power control and soft switching operation. A prototype was built for experiments. The experimental results show that with a supply voltage of $300 \mathrm{~V}$, coupling factor of 0.2 , and load resistance of $10 \Omega$, the output power can be controlled nearly linearly by the time of the energy injection stage in a range of 40-60 $\mu$ s, and the system works under soft switching conditions.
\end{abstract}

Keywords: inductive power transfer (IPT); Wireless Power Transfer (WPT); decoupled; soft switching; energy injection

\section{Introduction}

The inductive power transfer (IPT) system is a method of delivering power from a source to a load wirelessly, with the advantages of flexibility, safety, and convenience. IPT system has been widely used in wireless power transfer (WPT) systems, such as mobile phones [1], medical transplants [2], and electric vehicle (EV) charging applications [3-7]. IPT system has a pair of coils, which can be regarded as a loosely coupled transformer [8,9]. However, in a loosely coupled transformer, the leakage inductance is large and the coupling between the primary and secondary side is weak, resulting in low efficiency and power. To solve this problem, the resonant networks are employed on the primary and secondary side to compensate the reactive power caused by the leakage inductance [10]. Previous literature has studied the compensation methods. These methods include the basic topologies of $\mathrm{S} / \mathrm{S}$, $\mathrm{S} / \mathrm{P}, \mathrm{P} / \mathrm{S}$, and $\mathrm{P} / \mathrm{P}[11,12]$, together with the hybrid compensation topologies, such as LCL $[3,13]$ and LLC [14]. These works partly solved the low power and low efficiency caused by the leakage of the loosely coupling transformer, and made the IPT system work well under stable conditions.

However, the resonant frequency is significantly varied as the magnetic coupling between the primary coil and secondary coil changes due to the air-gap variation, lateral misalignment, and longitudinal movement [15]. These variations will lead to changes in coefficients of the loosely coupling transformer and frequency drift, resulting in frequency detuning and decreases in efficiency and power [15-18]. Some methods using phase-locked loop (PLL) are employed for frequency tracking. 
Matysik [19] introduces a frequency tracking method by adjusting the phase shift of current and voltage in resonant tank. Gati et al. [20] employs a digital PLL to zero the phase shift of the secondary current and the voltage of inverter. Using this method, the system can track the frequency well. However, to ensure the soft switching conditions, switching should occur at zero (near-zero) current. Therefore, an integrated control method [21] should be used to control the switches of the converter.

In the IPT systems, input voltage or load often changes, and it is necessary to change the power delivered to the primary side or secondary side. Therefore, power flow control plays an important role in the optimization of the IPT system's operation [22]. Traditional power control methods include reactive power control [23], frequency control [24] and phase shifting [25]. However, these power control methods still have problems such as the switching losses and electromagnetic noise, due to the operating devices are not always under soft switching conditions [26,27].

By dividing the energy transmission process into an energy injection stage and a self-tuning resonance stage (the converter maintain resonance by self-oscillation), the power can be controlled by the cycle number of the self-tuning resonance [28,29]. In these methods, all switching of the devices operate at the zero-crossing point of the primary current. Similar to the phase-locked loop control method, this power control method also needs switching operation at zero-crossing point of primary current. Therefore, the integrated control method should be used too for soft switching operation.

As mentioned in [21], to implement the integrated control methods, the supported hardware and control algorithm are needed. The hardware usually includes special signal unit, dead time pulse unit, phase-locked generator, and some logic devices. That is to say, a complex control circuit and control process are needed.

The complex control of the IPT system is due to the strong coupling between the resonant network and the converter. The operation of the converter is required to match the resonant network. If the converter can be decoupled from the resonant network during the energy injection period, the operation of the converter will not be restricted by the resonant network. Without the restriction of resonant network, the converter switches may be easily operated under soft switching condition, and the power flow may be easily controlled [30].

This paper presents a converter for IPT system based on independently inductive energy injection and free resonance (IIEIFR) control strategy. In contrast to traditional converters, the proposed converter has independent energy injection topology and free oscillation topology. The control strategy is different from the traditional converters either. With the proposed control strategy, the resonant tank is completely isolated from the power supply in the energy injection stage, and the power source injects energy into the inductor independently.

The proposed converter has two operating states: energy injection state and free resonance state. In the energy injection state, the primary inductor is isolated from the resonance network and connected to the power source. The power source independently injects energy into the primary inductor. In the free resonance state, the primary inductor is isolated from the power source and connected back to the resonance network, and the system begins to resonate freely. Two semiconductor devices are used as two double-throw switches to switch the system between the two states. Since the energy injection state and the resonance state are isolated from each other, the converter can be decoupled from the resonance network by using IIEIFR control strategy. This IPT system has the following characteristics:

(1) Energy injection process is not affected by the resonance network. Therefore, the power flow can be independently controlled by changing the period of the energy injection stage.

(2) There is no energy backflow in the free resonance state, and the reactive power can be eliminated.

(3) Two time margins of the state transition are applied in the proposed control strategy. Therefore, there are soft switching time periods in the switching operation and the switches need not to be switched at zero current crossing point. 


\section{Basic Structure and System Models}

\subsection{Structure of the IIEIFR IPT System}

A sketch of the IIEIFR IPT system is shown in Figure 1. It consists of a power source $U_{\mathrm{DC}}$, a primary tank capacitor $C_{\mathrm{p}}$, a primary inductor $L_{1}$, a secondary tank capacitor $C_{\mathrm{s}}$, a secondary inductor $L_{2}$, a double-throw switches $\mathrm{K}$ and a load resistance $R . M$ is the mutual inductance between $L_{1}$ and $L_{2}$. $L_{1}, L_{2}$, and $M$ can be described as a loosely coupled transformer $\mathrm{T}$.

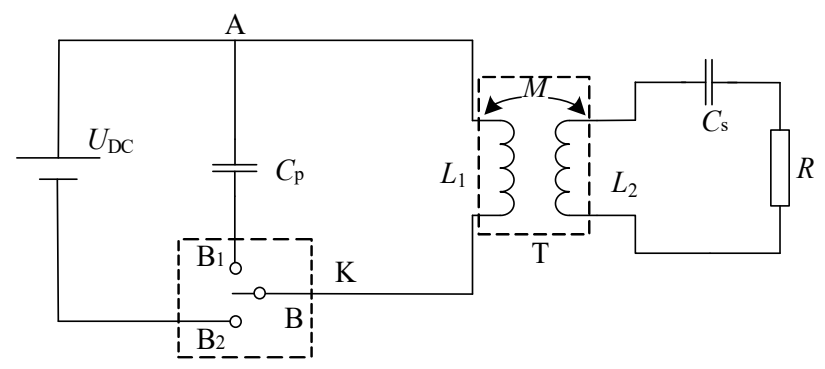

Figure 1. The conceptual schematic of the IIEIFR system.

The fixed end of switch $\mathrm{K}$ is identified as $\mathrm{B}$, and the switchable ends of $\mathrm{K}$ are identified as $\mathrm{B}_{1}$ and $\mathrm{B}_{2}$, respectively. According to the connection states of $\mathrm{K}$, the IIEIFR IPT system can work in three stages:

(1) Energy injection stage. In this stage, $\mathrm{B}$ is connected to $\mathrm{B}_{2} . U_{\mathrm{DC}}$ is connected to $L_{1}$ and $L_{1}$ is isolated from $C_{\mathrm{p}} . U_{\mathrm{DC}}$ independently injects energy into the primary coil. In this stage, part of the energy is transferred to the secondary coil, as shown in Figure 2a. In Figure 2, the activated circuit parts were indicated by solid lines and inactive circuit parts were indicated by dashed lines.

(2) Free resonance stage. In this stage, $\mathrm{B}$ is connected to $\mathrm{B}_{1}$. $U_{\mathrm{DC}}$ is isolated from $L_{1}$, and $C_{\mathrm{p}}$ is connected to $L_{1}$ to form a resonant tank and the system begins to resonate, as shown in Figure $2 \mathrm{~b}$. The energy continues to be transferred to the secondary coil.

(3) Shutdown stage. $\mathrm{B}$ is switched to the center point, not connected to either $\mathrm{B}_{1}$ or $\mathrm{B}_{2}$, where $U_{\mathrm{DC}}$, $C_{\mathrm{p}}$, and $L_{1}$ are isolated from each other, as shown in Figure $2 \mathrm{c}$. In this stage, the system stops transferring energy to the secondary part and the remaining energy is stored in the capacitor $C_{p}$ as electrical energy.

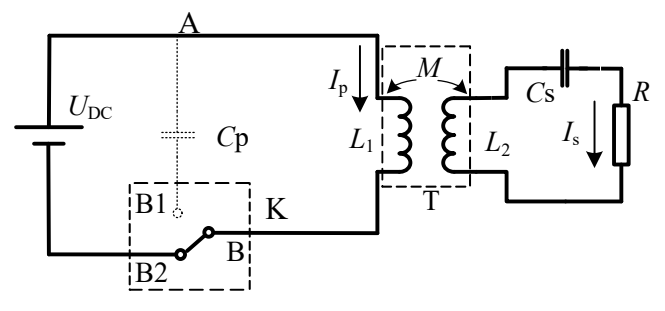

(a)

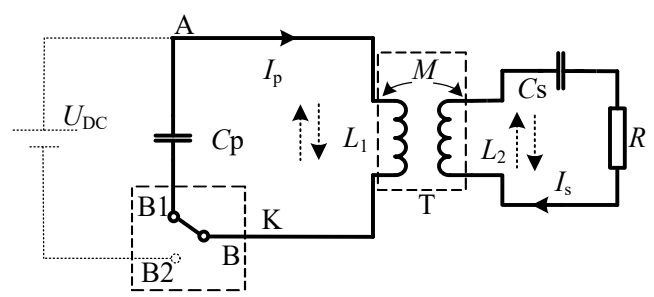

(b)

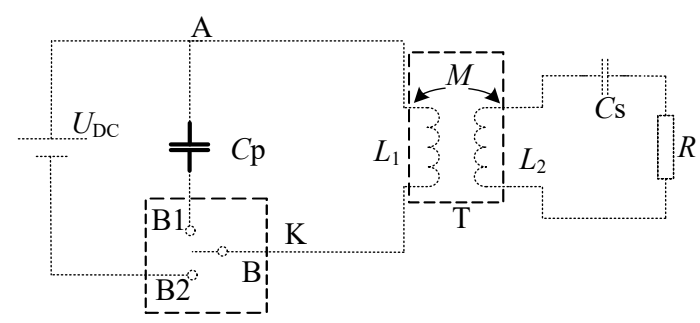

(c)

Figure 2. Schematic diagram of IIEIFR system. (a) Energy injection stage; (b) Free resonance stage; (c) Shutdown stage. 


\subsection{System Modeling}

\subsubsection{Energy Injection Stage}

In this stage, the primary inductor is connected to the power source, and Figure 1 can be simplified to Figure 3a. In Figure $3 a, N_{1}$ and $N_{2}$ are the turns of the primary and secondary coils, respectively (in this study, $N_{1}=N_{2}$ ). With the coupled inductors model (M model), Figure 3a can be represented by Figure $3 b$.

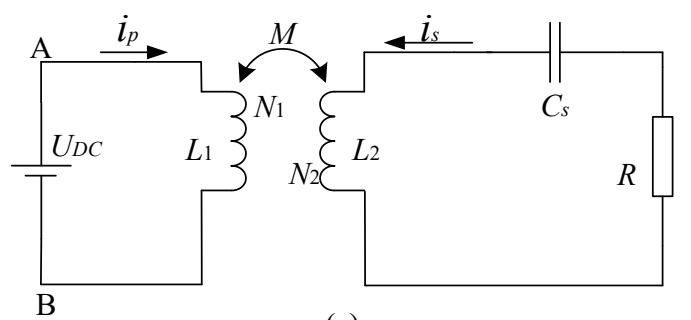

(a)

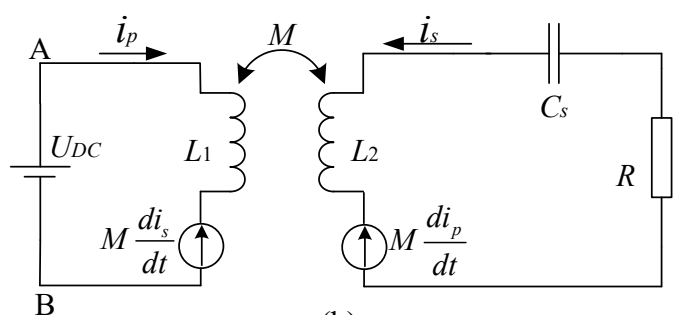

(b)

Figure 3. Circuit models in the energy injection stage (a) simplified circuit model; (b) equivalent circuit model.

In Figure $3 \mathrm{~b}, i_{\mathrm{p}}$ is the primary current; $i_{\mathrm{s}}$ is the secondary current. Coupling capacity between primary and secondary can be expressed by coupling coefficient $k$, then there is:

$$
k=\frac{M}{\sqrt{L_{1} L_{2}}}
$$

\subsubsection{Free Resonance Stage}

In the free resonance stage, the primary inductor $L_{1}$ is connected with the capacitor $C_{\mathrm{p}}$ to form a resonance tank, and Figure 1 can be illustrated as Figure 4a. Since the currents in the primary inductor and secondary inductor are sinusoidal, Figure $4 \mathrm{a}$ can be simplified to Figure $4 \mathrm{~b}$.

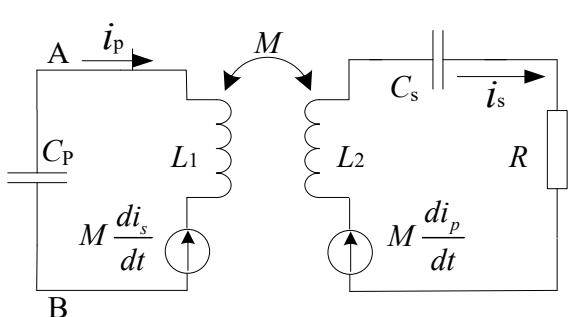

(a)

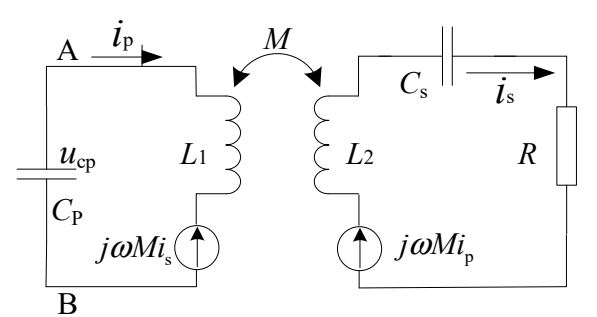

(b)

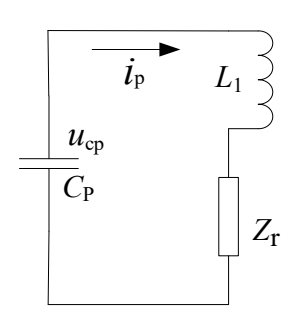

(c)

Figure 4. Circuit models in the free resonance state stage: (a) simplified circuit model; (b) equivalent circuit model under sinusoidal condition; (c) equivalent circuit of the primary.

According to the method provided in the literature [12,31], secondary impedance can be expressed as

$$
Z_{s}=j \omega L_{2}+\frac{1}{j \omega C_{s}}+R
$$

The loading effect of the secondary side on the primary side can be shown as a reflected impedance, as shown in Figure 4c. there is

$$
Z_{r}=\frac{\omega^{2} M^{2}}{Z_{s}}
$$


Assuming $\sqrt{L_{1} C_{p}}=\sqrt{L_{2} C_{s}}$, the frequency of the system in the free resonance mode is

$$
\omega=\frac{1}{\sqrt{L_{1} C_{p}}}=\frac{1}{\sqrt{L_{2} C_{s}}}
$$

In this case, the reactance of $Z_{\mathrm{s}}$ is zero, and the reflected impedance is reduced to a resistance $R_{\mathrm{C}}=\operatorname{Re}\left\{Z_{\mathrm{r}}\right\}$.

\section{IIEIFR Power Converter}

\subsection{Topology of the IIEIFR IPT System}

The system configuration of an IIEIFR IPT system is shown in Figure 5. In Figure 5, $\mathrm{S}_{1}$ and $\mathrm{S}_{2}$ are employed to perform the function of the double-throw switch as shown in Figure $1 . \mathrm{D}_{3}$ is anti-backflow diode. $\mathrm{T}$ is the loosely coupled transformer used for energy transmission with primary and secondary coils. $L_{1}$ is the inductance of primary coil and $L_{2}$ is the inductance of secondary coil, $k$ is the coupling coefficient. $C_{\mathrm{p}}$ is the primary resonant capacitor and $C_{\mathrm{s}}$ is the secondary resonant capacitor. One terminal of the primary coil is connected to the positive electrode of the power source, and the other terminal is connected to point $B$ between $S_{1}$ and $S_{2}$. When $S_{1}$ is turned on and $S_{2}$ turned off, point $B$ is connected to $C_{p}$, and the system is in the free resonance stage. When $S_{1}$ is turned off and $S_{2}$ is tuned on, point $B$ is connected to the negative electrode of the power source, and the system is in the energy injection stage. To prevent $C_{\mathrm{p}}$ directly connecting to the power source to generate surge current, a control strategy is used to ensure that $S_{1}$ and $S_{2}$ do not be turned on simultaneously.

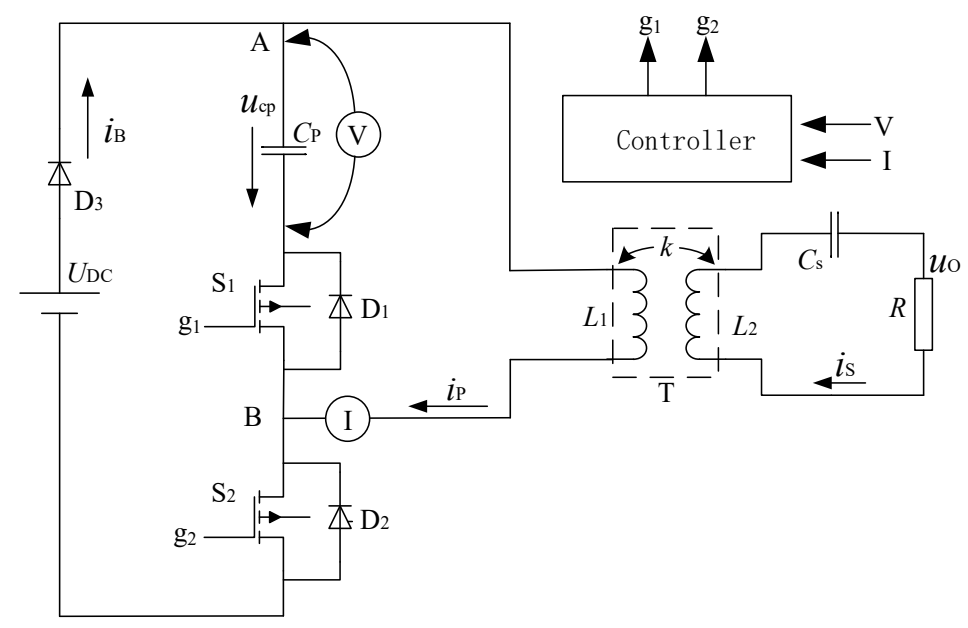

Figure 5. The structure of IIEIFR converter.

A voltage sensor is used to detect the voltage across the $C_{\mathrm{p}}$ and a current sensor is used to detect the primary current flowing through $L_{1}$, and a controller is employed to control the operation of the system. Signals of the sensors are sent to the controller, and the control strategy of the controller generates control signals, $g_{1}, g_{2}$, to control $S_{1}$ and $S_{2}$, respectively.

\subsection{State Analysis}

Figure 6 shows the state transition process of an IIEIFR converter. The steps of the state transition are indicated by schematic diagrams, and each step is indicated by a consecutive number from (1) to (5). The energy transmission process of the IIEIFR converter can be divided into 3 main states and 2 transitional states. The main states are energy injection state (state (1)); free resonance state (state (3), and shutdown stage (state (5)). The transition states are transition state between the energy state and the free resonance state (state (2)); transition state between the free resonance state and shutdown state (state (4)). Big arrows are used to indicate the order of state transitions. The current-carrying devices 
and circuit parts are indicated by black solid line, and the voltage-blocking devices and circuit parts are indicated by dashed lines.

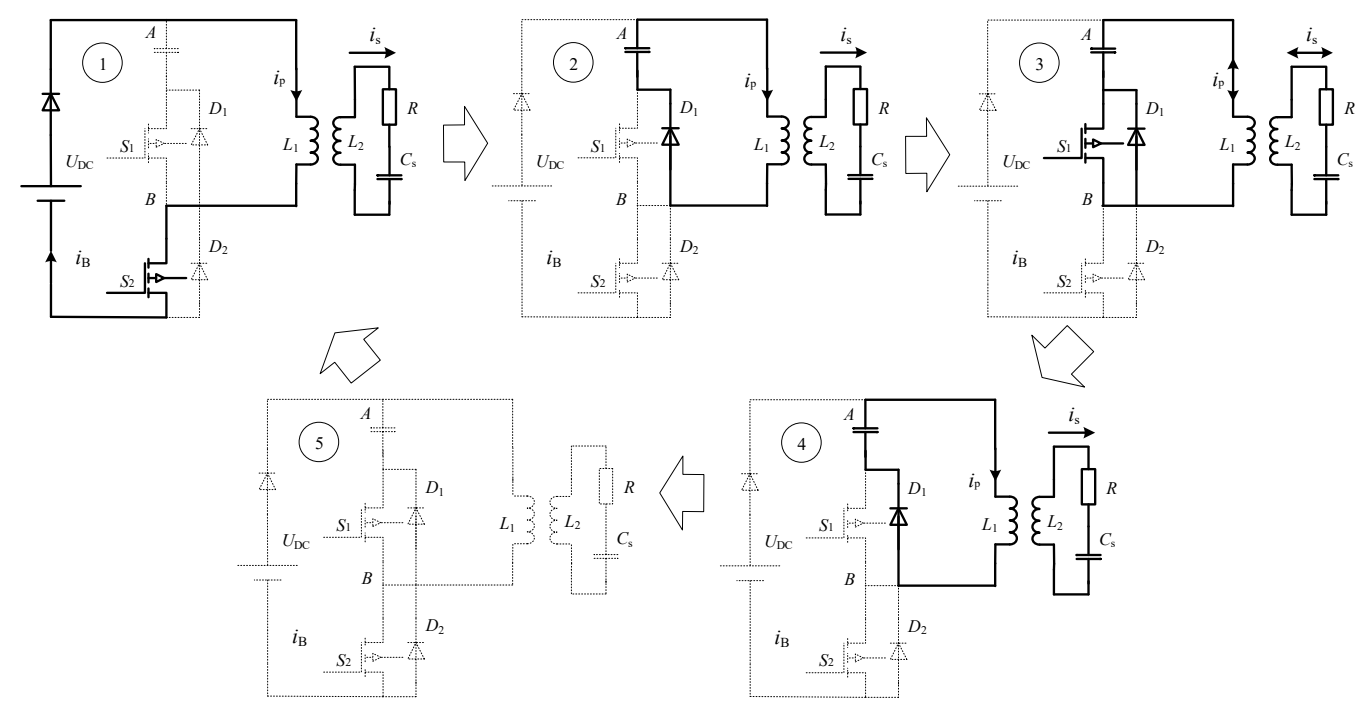

Figure 6. State transitions of the IIEIFR converter.

The waveforms of $u_{\mathrm{cp}}, i_{\mathrm{p}}$ and $i_{\mathrm{B}}$ of the IIEIFR converter in an energy transmission period is illustrated in Figure 7. Each state is also represented by a consecutive number in Figure 7, which is consistent with those in Figure 6.

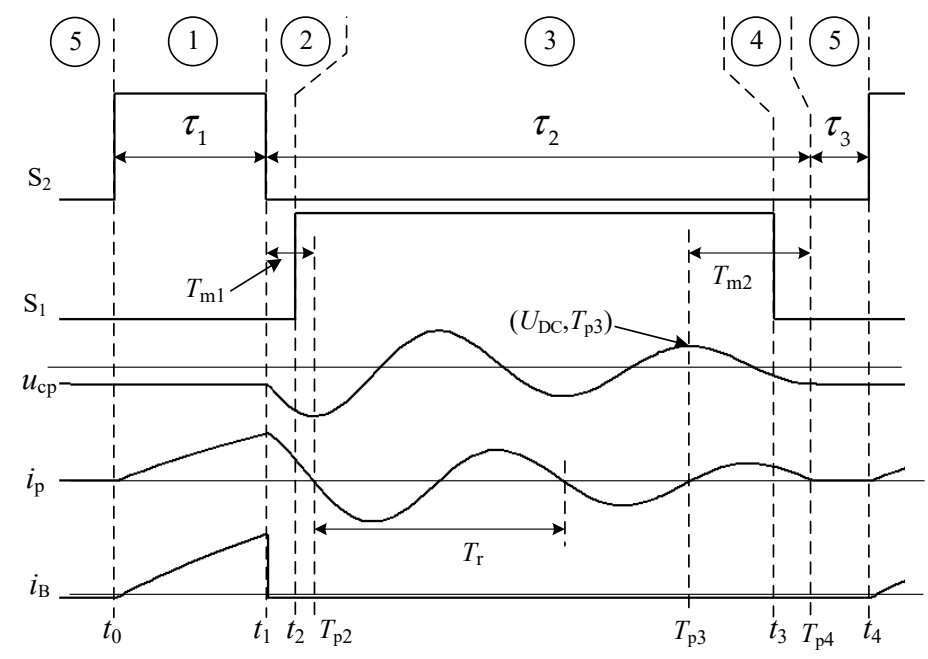

Figure 7. The waveforms of the bus current, primary current, and tank capacitor voltage of the IIEIFR converter.

As shown in Figures 6 and 7, the working principle and states of the IIEIFR converter are analyzed as follows:

State (5) $\left[t<t_{0}\right]$ : Shutdown state of the former energy transfer period. In this state, $S_{1}$ and $S_{2}$ are all turned off, the current of $L_{1}$ is zero, and the voltage across $C_{p}$ is $-U_{\mathrm{DC}}$. The energy remaining in the former period is stored in the $C_{\mathrm{p}}$.

State (1) $\left[t_{0}, t_{1}\right]$ : This state is the energy injection state, indicated as the energy injection period of $\tau_{1}$ in Figure 7. In this state, $S_{1}$ is turned off and $S_{2}$ is turned on, the point $B$ is connected to negative electrode of the power source $U_{\mathrm{DC}}$, and the primary inductor is connected to $U_{\mathrm{DC}}$. The source current $i_{\mathrm{B}}$ and the primary inductor current $i_{\mathrm{p}},\left(i_{\mathrm{B}}=i_{\mathrm{p}}\right)$ flow through $\mathrm{S}_{2}$, increasing linearly from zero, and 
$U_{\mathrm{DC}}$ injects energy into the primary inductor $L_{1}$. As $S_{1}$ is turned off, $C_{\mathrm{p}}$ is separated from point $\mathrm{B}, C_{\mathrm{p}}$ and $L_{1}$ are isolated from each other, and $u_{\mathrm{cp}}$ is maintained at $-U_{\mathrm{DC}}$. In this way, the power source is decoupled from the resonant tank.

According to Figure $3 b$, the voltage and current equation of state (1) are:

$$
\left\{\begin{array}{c}
U_{D C}=L_{1} \frac{d i_{p}}{d t}+M \frac{d i_{s}}{d t} \\
M \frac{d i_{p}}{d t}=L_{2} \frac{d i_{s}}{d t}+R i_{s}+\frac{1}{C_{s}} \int i_{s} d t
\end{array}\right.
$$

As shown in Figure 7, at time $t_{0}$, there is $i_{\mathrm{p}}\left(t_{0}\right)=0$. For convenience of analysis, let $t_{0}=0$. From Figure $3 \mathbf{b}$ and Equation (1), and assume $L=L_{1}=L_{2}$, it can be got that:

$$
\left\{\begin{array}{c}
i_{p}^{\prime}(0)=\frac{U_{D C}}{\left(1-k^{2}\right) L} \\
i_{p}(0)=0
\end{array}\right.
$$

Using Equation (6) as the boundary condition, solve Equation (5) and get

$$
i_{p}=\frac{k^{2} U_{D C}}{\left(1-k^{2}\right) \omega L} e^{-\alpha t} \sin \omega t+\frac{U_{D C}}{L} t
$$

where

$$
\left\{\begin{array}{c}
\alpha=\frac{R}{2\left(1-k^{2}\right) L} \\
\omega=\sqrt{\left.\frac{1}{\left(1-k^{2}\right) L C_{p}}\right)-\left(\frac{R}{2\left(1-k^{2}\right) L}\right)^{2}}
\end{array}\right.
$$

IPT system generally works in low coupling coefficient condition $(k<0.3)$ [32], therefore, the first term of the Equation (7) can be ignored, and the Equation (7) can be simplified as

$$
i_{p}=\frac{U_{D C}}{L} t
$$

Equation (9) indicates that the IIEIFR converter input current increases linearly and is not affected by other factors during the energy injection state. This characteristic enables the IIEIFR IPT system to conveniently control output power.

At $t_{1}, i_{\mathrm{p}}$ reaches the maximum as $i_{p}\left(t_{1}\right)$. Define $\tau_{1}=t_{1}-t_{0}$ as the energy injection period, there is

$$
i_{p}\left(\tau_{1}\right)=\frac{U_{D C}}{L} \tau_{1}
$$

In the energy injection period, the magnetic energy injected into the primary inductor by the power source is

$$
W_{m}=\frac{1}{2} L i_{p}^{2}\left(\tau_{1}\right)
$$

As can be seen in Figure 7 , before $t_{1}$, the voltage of $u_{\mathrm{cp}}$ is maintained at $-U_{\mathrm{DC}}$, which indicates that the $C_{\mathrm{p}}$ stores the remained energy in the previous energy transmission period.

When the system is switched from the energy injection state to the free resonance state, this residual energy needs to be added to the resonance network. Therefore, a transition state is required to do this.

State (2) $\left[t_{1}, t_{2}\right]$ : This state is the transitional state between the energy injection state and the free resonance state. In this state, $S_{2}$ is turned off, and $D_{1}$ is turned on. The current $i_{\mathrm{p}}$ does not flow through $\mathrm{S}_{2}$ but through $\mathrm{D}_{1}$ to charge the capacitance $C_{\mathrm{p}}$, and $i_{\mathrm{B}}$ is interrupted. With charging to $C_{\mathrm{p}}$ by $i_{\mathrm{p}}, u_{\mathrm{cp}}$ decreases from $-U_{\mathrm{DC}}$ and $i_{\mathrm{p}}$ decreases from the maximum current $i_{p}\left(\tau_{1}\right)$. By this way, the energy stored in $C_{\mathrm{p}}$ is added to the resonance network. Since at this time the circuit was in resonance, both $i_{\mathrm{p}}$ and $u_{\mathrm{cp}}$ drop sinusoidally. At $T_{\mathrm{p} 2}, u_{\mathrm{cp}}$ drops to the lowest point while $i_{\mathrm{p}}$ drops to zero. 
Note in the interval $\left[t_{1}, T_{\mathrm{p} 2}\right], \mathrm{D}_{1}$ maintains in on state, and the voltage across $\mathrm{S}_{2}$ is zero, which creates zero voltage switch (ZVS) condition of turning on $S_{2}$. Therefore, the interval $\left[t_{1}, T_{\mathrm{p} 2}\right]$ can be defined as a time margin, $T_{\mathrm{m} 1}$ for turning on $\mathrm{S}_{2}$ under ZVS condition when the system transitions from state (1) to state (2). During $T_{\mathrm{m} 1}$, a certain $t_{2}$ is chosen to turn on $S_{1}$, and the system is switched to the free resonance state.

State (3) $\left[t_{2}, t_{3}\right]$ : This state is the free resonance state. Since both $S_{1}$ and $D_{1}$ are alternately turned on in this state, point $B$ is connected to the capacitor $C_{p}$, and $L_{1}$ and $C_{p}$ form a resonant tank. As the system begins to resonant, the energy is transferred to the secondary side, and the amplitudes of the $u_{\mathrm{cp}}$ and $i_{\mathrm{p}}$ decrease exponentially.

When the amplitude of $u_{\mathrm{cp}}$ drops to $U_{\mathrm{DC}}$, (at $T_{\mathrm{p} 3}$, as shown in Figure 7), most of the injected energy has been sent to the secondary side. Therefore, when the voltage sensor (as shown in Figure 5) detects $u_{\mathrm{cp}}=U_{\mathrm{DC}}$, the controller executes a program to make the system exit from the free resonance state. A transition state is needed to convert magnetic energy into electric energy before exiting the free resonance state.

State (4) $\left[t_{3}, t_{4}\right]$ : This state is the transitional state between the free resonance state and shutdown state. As shown in Figure 7 , at time moment $T_{\mathrm{p} 3}$, the amplitude of $u_{\mathrm{cp}}$ drops to $U_{\mathrm{DC}}$, and correspondingly $i_{\mathrm{p}}$ is zero. After $T_{\mathrm{p} 3}$ moment, $i_{\mathrm{p}}$ flows forward to charge $C_{\mathrm{p}}$ through $\mathrm{D}_{1}$. With the charging of $C_{\mathrm{p}}$, the magnetic energy is converted into electrical energy. At time moment $T_{\mathrm{p} 4}, i_{\mathrm{p}}$ drops to zero again and $u_{\mathrm{cp}}$ reaches to $-U_{\mathrm{DC}}$. This means that all magnetic energy has been converted into electric energy. If an appropriate $t_{3}$ is chosen to turn off $S_{1}$ in the interval $\left[T_{\mathrm{p} 3}, T_{\mathrm{p} 4}\right]$, the backflow path of $i_{\mathrm{p}}$ will be blocked. Therefore, $i_{\mathrm{p}}$ will be zero after $T_{\mathrm{p} 4}$, and $u_{\mathrm{cp}}$ will remain at $-U_{\mathrm{DC}}$ until the next energy transfer period.

In this state, as the switch control strategy is based on voltage and current sensors, the condition to turn off $S_{1}$ is that $i_{\mathrm{p}}$ must be positive and in the time interval $\left[t_{3}, t_{4}\right]$. If $i_{\mathrm{p}}$ is not positive due to load change, $S_{1}$ will not be turned off because it does not meet the turn-off condition. The turn-off action will be postponed to the next cycle (after the system is stable).

In the interval $\left[T_{\mathrm{p} 3}, T_{\mathrm{p} 4}\right], \mathrm{D}_{1}$ is in on state, which creates $\mathrm{ZVS}$ condition of turning off $\mathrm{S}_{1}$. Therefore, the interval $\left[T_{\mathrm{p} 3}, T_{\mathrm{p} 4}\right]$ can be defined as the time margin $T_{\mathrm{m} 2}$, for turning off $\mathrm{S}_{1}$ when system is to exit the free resonance state.

In fact, the system is in the same resonance period in states (2), (3), (4), and the interval $\left[t_{1}, T_{\mathrm{p} 4}\right]$ can be defined as a free resonance period $\tau_{2}$, as shown in Figure 7 . In the interval $\left[t_{1}, T_{\mathrm{p}}\right]$, Figure 5 is equivalent to the circuit shown in Figure $4 b$, and the voltage equation is shown as

$$
0=L_{1} \frac{d i_{\mathrm{p}}}{d t}+i_{\mathrm{p}} R_{\mathrm{C}}+\frac{1}{C_{p}} \int i_{\mathrm{p}} d t
$$

According to [27,33], the solution of Equation (12) is

$$
i_{p}=I_{p m} e^{-\alpha_{r} t} \sin \left(\omega_{r} t+\theta\right)
$$

where

$$
\left\{\begin{array}{c}
\alpha_{r}=\frac{R_{C}}{2 L} \\
\omega_{r}=\frac{1}{\sqrt{L_{1} C_{p}}}
\end{array}\right.
$$

Equation (13) has two unknown valuables to be solved, i.e., the amplitude $I_{p m}$, and phase lead angle $\theta$. In Figure 7 , it can be seen that at the moment $t_{1}, i_{\mathrm{p}}$ is the maximum $i_{p}\left(t_{1}\right)$, and $u_{c p}\left(t_{1}\right)$ is $-U_{\mathrm{DC}}$. According to Figure $4 \mathrm{~b}$, there is

$$
u_{c p}\left(t_{1}\right)=-\frac{i_{p}\left(t_{1}\right)}{\omega_{r} C_{p}}
$$


Let $t_{1}=0$, there are: $i_{p}(0)=i_{p}\left(t_{1}\right)=i_{p}\left(\tau_{1}\right), u_{c p}(0)=u_{c p}\left(t_{1}\right)=-U_{\mathrm{DC}}$. Substituting these initial conditions into Equation (13), there are

$$
\left\{\begin{array}{c}
i_{p}\left(\tau_{1}\right)=I_{p m} \sin \theta \\
U_{D C}=U_{c p m} \cos \theta \\
U_{c p m}=\frac{I_{p m}}{\omega_{r} C_{p}}
\end{array}\right.
$$

The amplitude $I_{\mathrm{pm}}$ and phase angle $\theta$ in Equation (13) can be obtained by solving Equation (16). There are

$$
\left\{\begin{array}{c}
I_{p m}=\sqrt{i_{p}\left(\tau_{1}\right)^{2}+\left(\omega_{r} C_{p} U_{D C}\right)^{2}} \\
U_{c p m}=\frac{\sqrt{i_{p}\left(\tau_{1}\right)^{2}+\left(\omega_{r} C_{p} U_{D C}\right)^{2}}}{\omega_{r} C_{p}} \\
\theta=\arctan \frac{i_{p}\left(\tau_{1}\right)}{\omega_{r} C_{p} U_{D C}}
\end{array}\right.
$$

State (5): The shutdown state. After $T_{\mathrm{p} 4}$, both $\mathrm{S}_{1}$ and $\mathrm{S}_{2}$ are turned off. The primary current $i_{\mathrm{p}}=0$ and the capacitor voltage $u_{\mathrm{cp}}=-U_{\mathrm{DC}}$. The circuit stopped transferring the energy temporarily and waited for the next energy transmission process.

\subsection{Parameter Settings}

\subsubsection{Time Parameters}

Time margins for state change $\left(T_{\mathrm{m} 1}=T_{\mathrm{p} 2}-t_{1}, T_{\mathrm{m} 2}=T_{\mathrm{p} 4}-T_{\mathrm{p} 3}\right)$. As shown in Figure $7, T_{\mathrm{m} 1}$ is the time of the lead angle of $i_{\mathrm{p}}$, and $T_{\mathrm{m} 2}$ is the time of half a cycle of $i_{\mathrm{p}}$. Therefore, $T_{\mathrm{m} 1}$ and $T_{\mathrm{m} 2}$ can be calculated by

$$
\left\{\begin{array}{l}
T_{m 1}=\frac{\theta}{\omega_{r}} \\
T_{m 2}=\frac{\pi}{\omega_{r}}
\end{array}\right.
$$

Maintenance time of free resonance state. Due to the low coupling coefficient, the energy injected into the resonant tank needs multiple cycles to be sent to the secondary side in $\tau_{2}$. As shown in Figure 7, two cycles are used to transfer energy to the secondary side in one energy transfer process. According to the different coupling coefficients, the cycle numbers in $\tau_{2}, n$, are different in an energy transmission process. Therefore, $\tau_{2}$ is a function of the coupling coefficient $k$.

As can be seen from $i_{\mathrm{p}}$ curve in Figure $7, \tau_{2}$ contains two resonant cycles and one $T_{\mathrm{m} 1}$, therefore, for the general case, $\tau_{2}$ can be expressed as

$$
\tau_{2}=n T_{r}+T_{m 1}
$$

where $n$ is the numbers of the free resonance cycle, and $T_{\mathrm{r}}$ is the period of the free resonance. The theoretical $n$ and $T_{\mathrm{r}}$ has been studied in [30] as

$$
\left\{\begin{array}{c}
n=\left[\frac{1}{\alpha_{r} T_{r}} \ln \frac{U_{c p m}}{U_{D C}}\right] \\
T_{r}=\frac{2 \pi}{\omega_{r}}
\end{array}\right.
$$

where [-] is the integer function. Please note that the number of the resonance cycles must be an integer.

\subsubsection{Output Power}

Since the switches of the converter operate under soft switching condition, the loss level of the converter is low. The energy injected in energy injection state can be considered to be all sent to the secondary coil. As shown in Figure 7, the time required for an energy transmission period is

$$
T_{e}=\tau_{1}+\tau_{2}+\tau_{3}
$$


According to Equations (11) and (21), the output power is

$$
P_{\text {out }}=\frac{W_{m}}{T_{e}}=\frac{\left(U_{D C} \tau_{1}\right)^{2}}{2 L T_{e}}=\frac{\left(U_{D C} \tau_{1}\right)^{2}}{2 L\left(\tau_{1}+\tau_{2}+\tau_{3}\right)}
$$

\section{Experimental Prototype}

To demonstrate the proposed topology of the IIEIFR IPT system, according to the topological structure of Figure 5, an experimental prototype was built. The prototype has a power capacity of $1000 \mathrm{~W}$ and consists of two parts: the power converter and the magneto-electric system.

\subsection{Magneto-Electric System}

The magneto-electric system is a pair of coil pad, and the pad structure is shown in Figure 8. An epoxy resin plate is placed on the bottom layer as a substrate. Several pieces of ferrites $(\mathrm{Mn}-\mathrm{Zn}$ ferrite PC40) are radially placed on the substrate to form a core layer. A copper coil is wound by Litz wires (diameter $500 \times 0.1 \mathrm{~mm}$ ) on the core layer. Upon the copper coil is a protective layer made of organic glass. The structure of the primary pad is the same as the secondary pad, and its geometric dimensions are listed in Table 1.

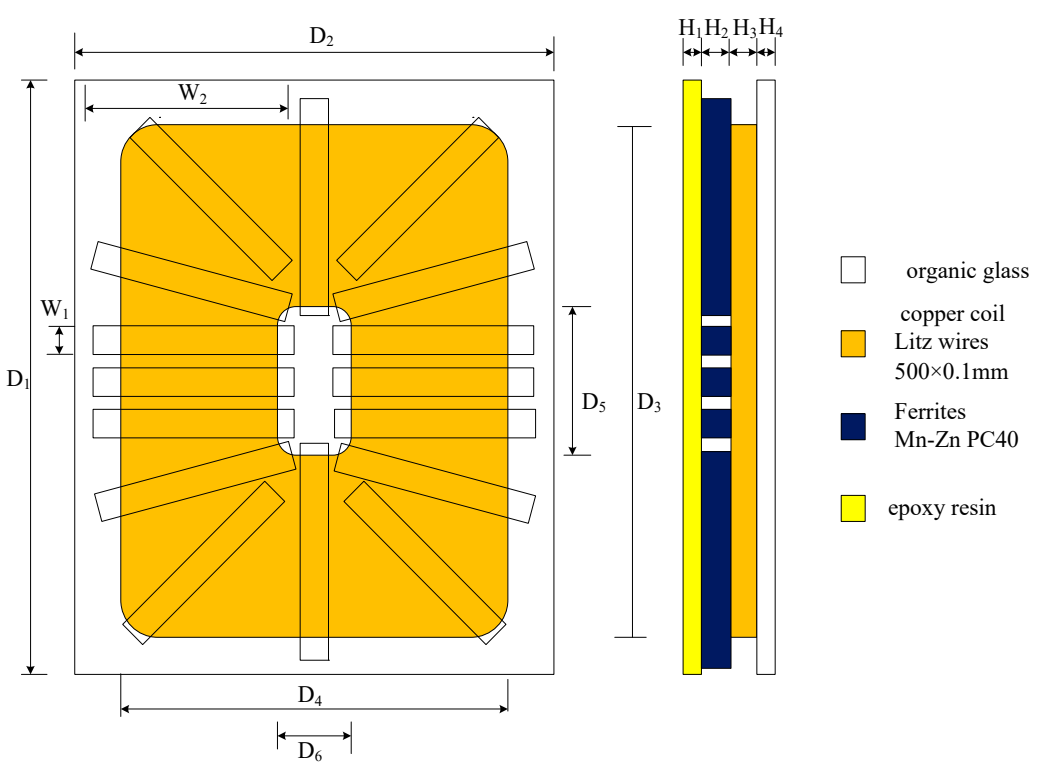

Figure 8. Structure of the pad used.

Table 1. Geometrical dimensions of the pads.

\begin{tabular}{cccccc}
\hline $\mathbf{D}_{\mathbf{1}}$ & $\mathbf{D}_{\mathbf{2}}$ & $\mathbf{D}_{\mathbf{3}}$ & $\mathbf{D}_{\mathbf{4}}$ & $\mathbf{D}_{\mathbf{5}}$ & $\mathbf{D}_{\mathbf{6}}$ \\
\hline $460 \mathrm{~mm}$ & $370 \mathrm{~mm}$ & $440 \mathrm{~mm}$ & $350 \mathrm{~mm}$ & $160 \mathrm{~mm}$ & $80 \mathrm{~mm}$ \\
\hline $\mathbf{H}_{\mathbf{1}}$ & $\mathbf{H}_{\mathbf{2}}$ & $\mathbf{H}_{\mathbf{3}}$ & $\mathbf{H}_{\mathbf{4}}$ & $\mathbf{W}_{\mathbf{1}}$ & $\mathbf{W}_{\mathbf{2}}$ \\
\hline $5 \mathrm{~mm}$ & $10 \mathrm{~mm}$ & $5 \mathrm{~mm}$ & $3 \mathrm{~mm}$ & $20 \mathrm{~mm}$ & $150 \mathrm{~mm}$ \\
\hline
\end{tabular}

The inductances of the coil pads are both $640 \mu \mathrm{H}$, and the mutual inductance between the pads varies with the air gap of the pads. The coupling coefficient versus air gap is shown in Figure 9, when the gap increases from $50 \mathrm{~mm}$ to $210 \mathrm{~mm}$, the coupling coefficient decreases from 0.51 to 0.06 respectively, matching the range of EV charging system, 0.1-0.33 [32]. 


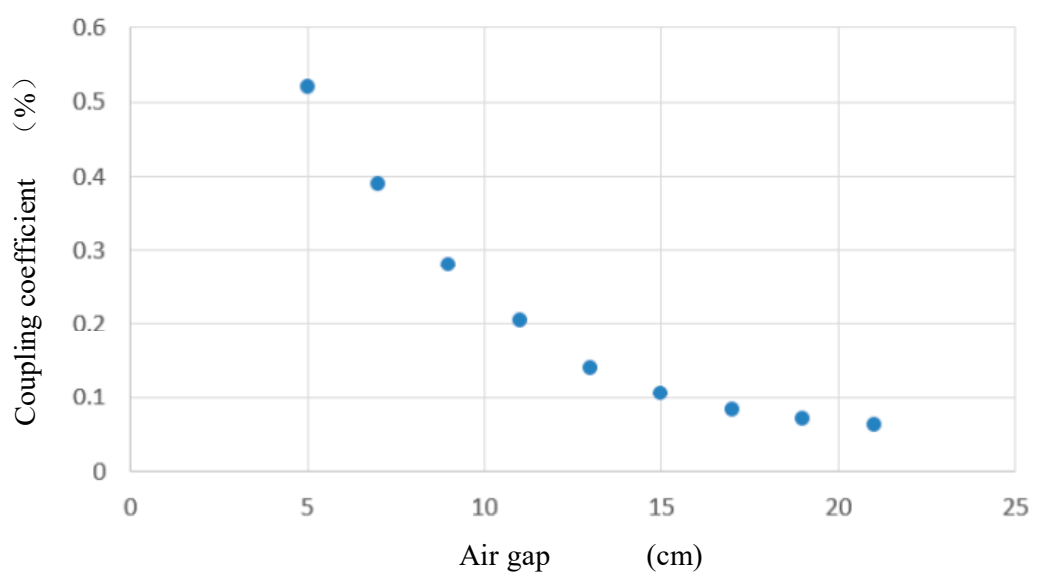

Figure 9. Coupling coefficient versus the air gap.

\subsection{Power Converter}

The prototype of the power converter that was built according the topology illustrated in Figure 5 is shown in Figure 10. The prototype parameters are shown in Table 2, and the controller of the prototype is the microprocessor STM32.

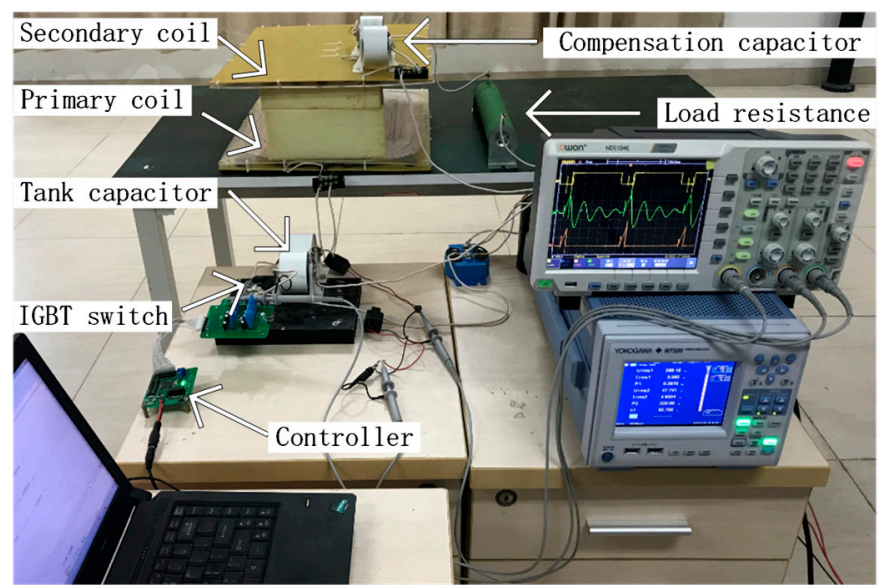

Figure 10. The prototype of the IIEIFR IPT system.

Table 2. Component values used in the prototype.

\begin{tabular}{cc}
\hline Parameter/Part & Value \\
\hline$U_{\mathrm{DC}}$ & $300 \mathrm{~V}$ \\
$C_{\mathrm{p}}$ & $0.88 \mu \mathrm{F}$ \\
$L_{1}, L_{2}$ & $640 \mu \mathrm{H}$ \\
$R$ & $10-50 \Omega$ \\
$\mathrm{S}_{1}, \mathrm{~S}_{2}$ & GD100HFU120C1S \\
\hline
\end{tabular}

\section{Simulation and Experimental Verification}

\subsection{Features of the IIEIFR ICP System}

In the processes of simulation and experiment, $\tau_{1}=70 \mu \mathrm{s}, \tau_{3}=50 \mu \mathrm{s}, k=0.2, U_{\mathrm{DC}}=300 \mathrm{~V}$ and $R=10 \Omega \cdot u_{\mathrm{g} 1}$ and $u_{\mathrm{g} 2}$ are control signal of $\mathrm{S}_{1}$ and $\mathrm{S}_{2}$, respectively. $u_{\mathrm{cp}}$ is the voltage of capacitor $C_{\mathrm{p}} \cdot i_{\mathrm{p}}$ is the current of $L_{1} \cdot i_{\mathrm{B}}$ is the current of power source. The simulation results using SABER (Synopsys, Mountain View, CA, USA) are shown in Figure 11. The experimental results are shown in Figure 12. These results are consistent with the descriptions in Figure 7 and Section 3.2. 


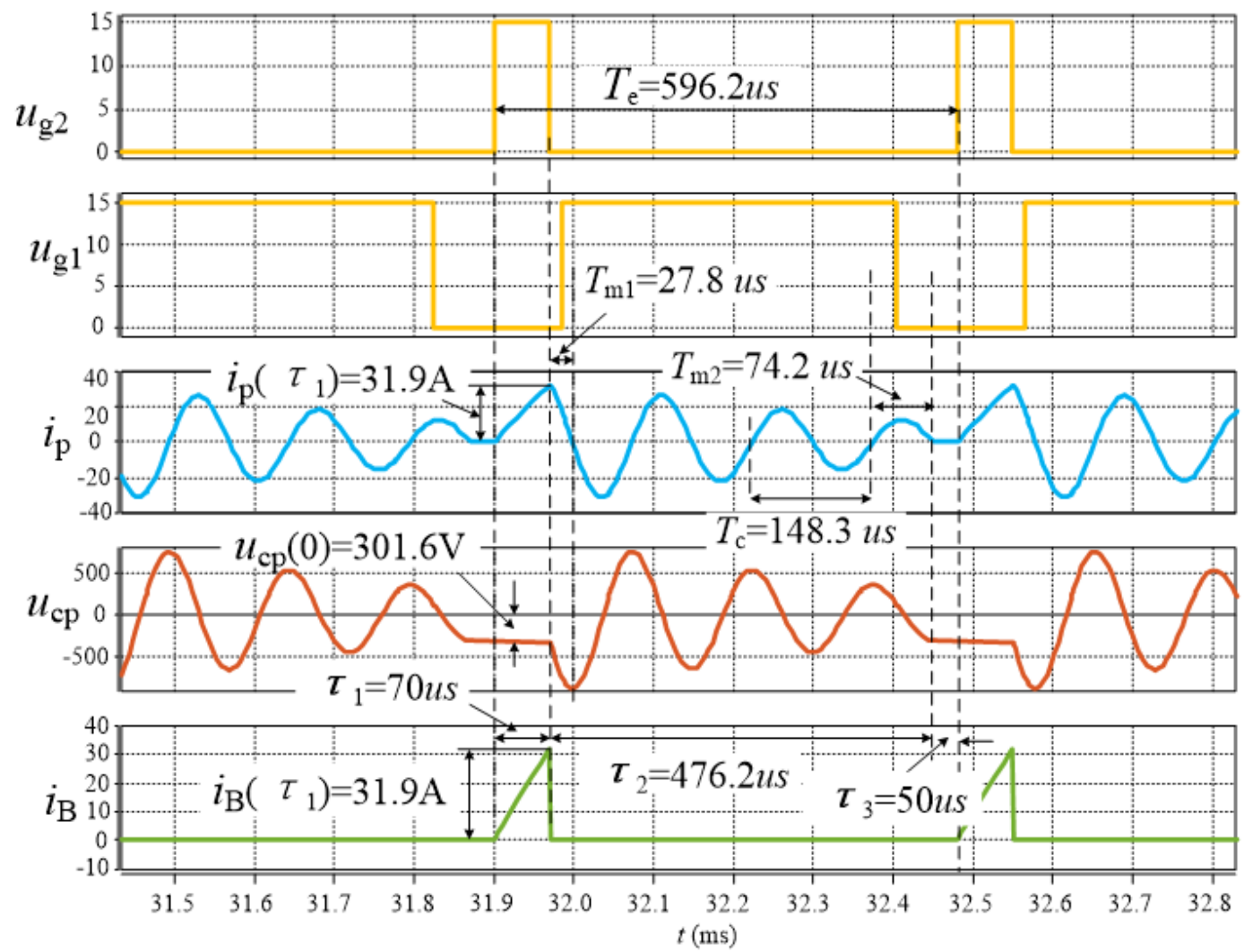

Figure 11. The simulation result of the IIEIFR ICPT system.

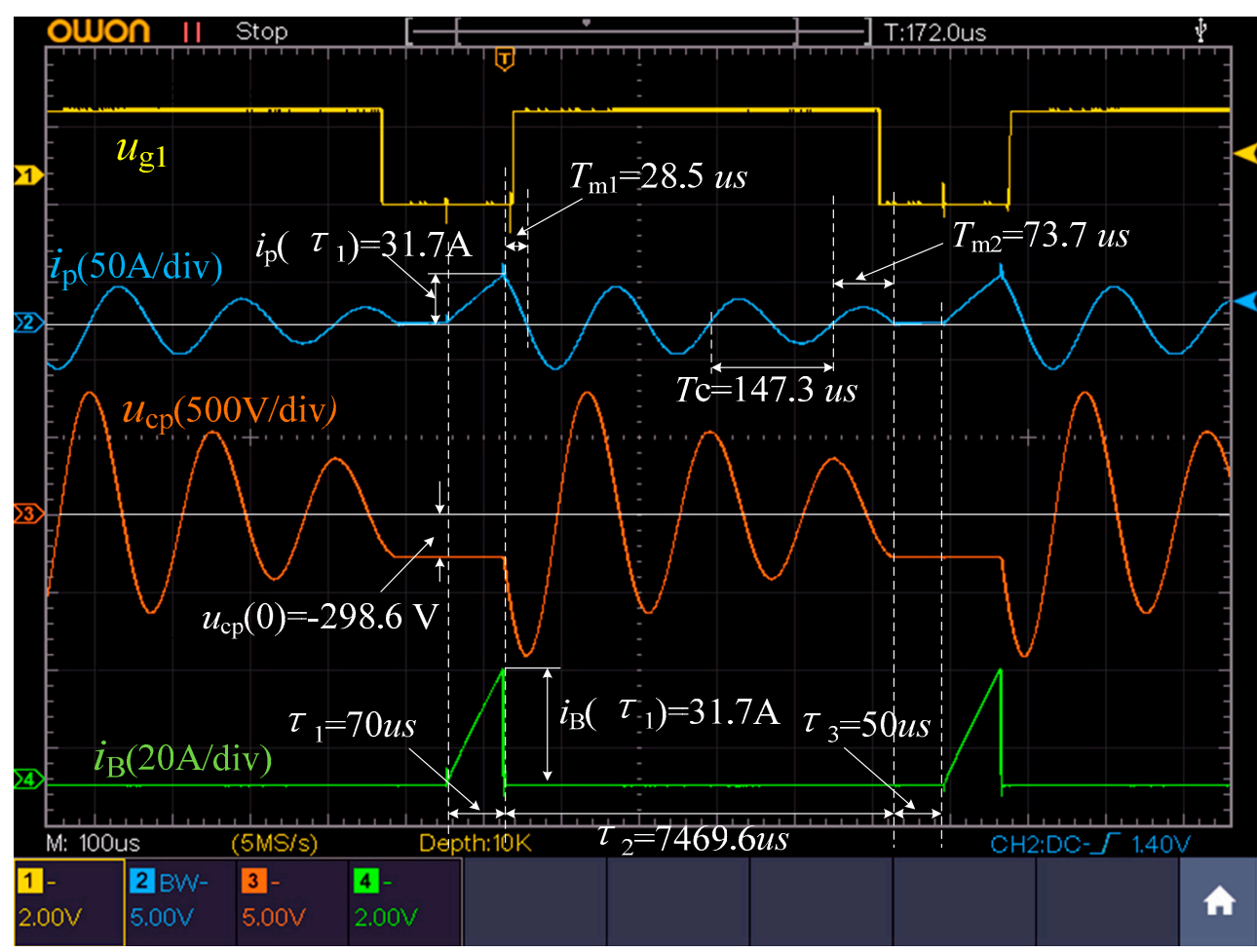

Figure 12. The experiment result of the IIEIFR ICP system.

Based on Figures 11 and 12, the analysis is shown below:

$\tau_{1}$ is the energy injection maintenance time, in this period, $i_{\mathrm{B}}$ and $i_{\mathrm{p}}$ rise linearly from zero. This indicates that the power source independently injects energy into the inductor $L_{1}$. At the end of $\tau_{1}$, 
$i_{\mathrm{B}}$ and $i_{p}$ rise to the maximum, $i_{\mathrm{B}}\left(\tau_{1}\right)$ and $i_{\mathrm{p}}\left(\tau_{1}\right)$. During this period, $u_{\mathrm{cp}}$ is at its initial value, $u_{\mathrm{cp}}=u_{\mathrm{cp}}(0)$, and remains unchanged because $C_{\mathrm{p}}$ is isolated from $L_{1} . \tau_{2}$ is the free resonance maintenance time. In this period, $i_{\mathrm{p}}$ and $u_{\mathrm{cp}}$ change sinusoidally, and $i_{\mathrm{B}}$ remains zero. This indicates that $C_{\mathrm{p}}$ and $L_{1}$ form a resonant tank and begin to resonate, and the power source is isolated from $L_{1}$, stopping the energy injection. Since energy is sent to the secondary side, the amplitudes of $i_{\mathrm{p}}$ and $u_{\mathrm{cp}}$ decrease exponentially during free resonance. At the end of $\tau_{2}, u_{\mathrm{cp}}$ returns to the initial value, $u_{\mathrm{cp}}=u_{\mathrm{cp}}(0)$ again, and $i_{\mathrm{p}}$ drops to zero, the free resonance stops. Simulation and experimental results show that energy injection and free resonance are independent of each other, which proves that the converter of the IIEIFR system is decoupled from the resonant network and there is no energy backflow.

According to Table 2, some parameters of this prototype were calculated by Equations (10)-(20) and listed in Table 3. Comparing Figure 11 with Table 3, it can be seen that the simulation and the experimental results are consistent with the theoretical calculation.

Table 3. The calculation results of the parameters marked in Figures 11 and 12.

\begin{tabular}{cccccc}
\hline$u_{\mathrm{cp}}(\mathbf{0})(\mathrm{V})$ & $\boldsymbol{i}_{\boldsymbol{p}}\left(\tau_{\mathbf{1}}\right)(\mathrm{A})$ & $\boldsymbol{T c}_{\mathrm{c}}(\boldsymbol{\mu s})$ & $\boldsymbol{T}_{\mathrm{m} \mathbf{1}}(\mu \mathrm{s})$ & $\boldsymbol{T}_{\mathrm{m} 2}(\mu \mathrm{s})$ & $\tau_{\mathbf{2}}(\mu \mathrm{s})$ \\
\hline 300 & 32.8 & 146 & 29 & 73 & 467.1 \\
\hline
\end{tabular}

$T_{\mathrm{m} 1}$ is the time margin for switching from the energy injection state to the free resonance state, it can be seen that $u_{\mathrm{g} 1}$ rises in this time margin to turn on $S_{1} . T_{\mathrm{m} 2}$ is the time margin for switching from the free resonance state to the shutdown state, it can be seen that $u_{\mathrm{g} 1}$ drops in this time margin to turn off $S_{1}$.

The period of $u_{\mathrm{g} 2}$ is the period of energy injection period, and the period of $u_{\mathrm{g} 2}$ is $T_{\mathrm{e}}=\tau_{1}+\tau_{2}+\tau_{3}$. $T_{\mathrm{c}}$ is the cycle of the free resonance, and there are three cycles of $i_{\mathrm{p}}$ in a period of $u_{\mathrm{g} 2}$, which means the IIEIFR converter can carry out high frequency energy transmission at low switching frequency, and this feature reduces the switching losses.

Figure 13 shows the waveforms of primary current, the secondary current (output current) and the voltage of the secondary capacitance, $\mathrm{Cs}$, under the conditions of: $U_{\mathrm{DC}}=300 \mathrm{~V}, R=10 \Omega, \tau_{1}=45 \mu \mathrm{s}$, $k=0.2$.

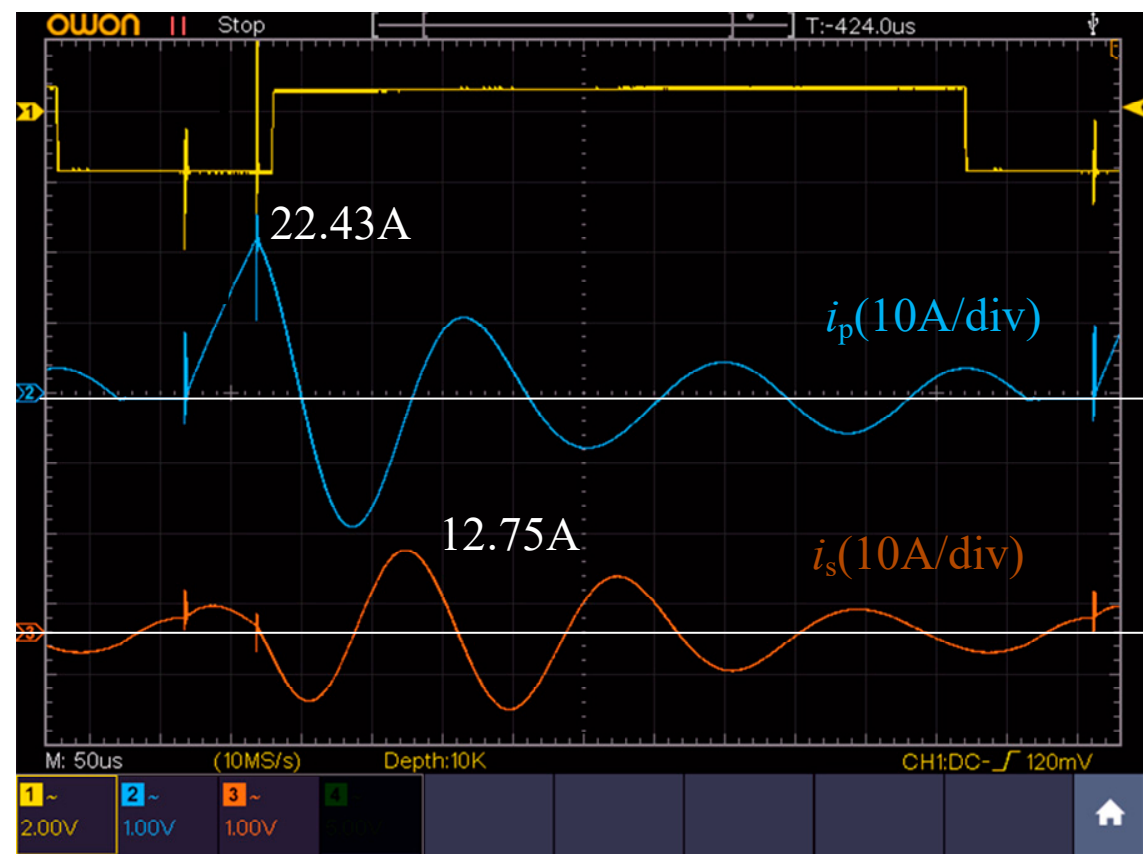

Figure 13. the waveforms of primary current (blue) secondary current (orange). 
The maximum value of the primary current is $22.43 \mathrm{~A}$, and the maximum value of the secondary current is $12.75 \mathrm{~A}$. The secondary current is continuous, and the fluctuation is smaller than the primary current.

\subsection{Power Control}

As discussed in Section 3.3.2, power can be controlled by energy injection period $\tau_{1}$. Figure 14 shows the experimental results of output power varying with $\tau_{1}$ under different coupling coefficients. The coupling coefficient is selected as $k=0.1,0.2,0.3$. When $\tau_{1}=40 \mu \mathrm{s}$, the output powers are $181.1 \mathrm{~W}$, 171.6 W, and 167.1 W. When $\tau_{1}=60 \mu \mathrm{s}$, the output powers are $379 \mathrm{~W}, 356.7 \mathrm{~W}$, and $335.8 \mathrm{~W}$. The results show that there is a linear relation between the output power and the energy injection period $\tau_{1}$. Under the same $\tau_{1}$ condition, the output power decreases slightly as $k$ increases. The reason of this phenomenon is that the increase of $k$ will lead to the decrease of leakage inductance and increase of the excitation inductance. The increase of excitation inductance results in a decrease of $i_{\mathrm{p}}$, and finally a decrease of output power.

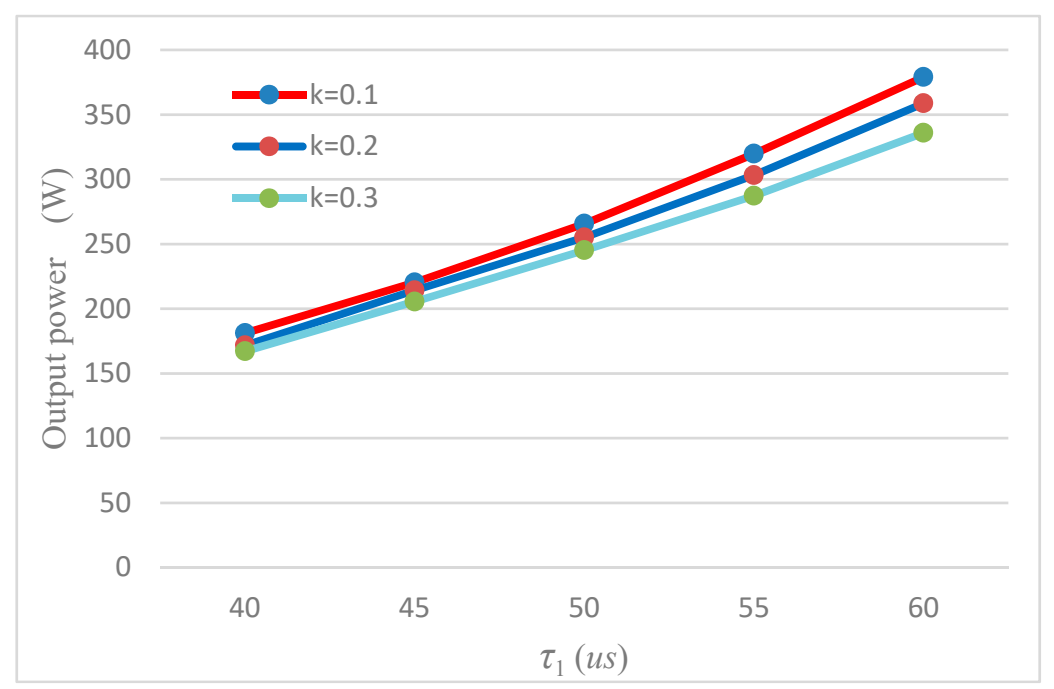

Figure 14. Output power versus the energy injection period $\tau_{1}$ under condition of $U_{\mathrm{DC}}=300 \mathrm{~V}$ and $R=10 \Omega$.

The experimental results of output power varying with $\tau_{1}$ under different load, $R$ are shown in Figure 15. It can be seen that there is still a good linearity between the output power and $\tau_{1}$. Using the curve of $R=10 \Omega$ as an example. When $\tau_{1}=40 \mu \mathrm{s}$, the output power is $171.6 \mathrm{~W}$; when $\tau_{1}=60 \mu \mathrm{s}$, the output power is $361.7 \mathrm{~W}$. This curve is consistent with the curve of $k=0.2$ in Figure 15. The output power varies slightly with the load $R$. When $\tau_{1}=40 \mu \mathrm{s}$, the output power variation $\Delta$, caused by varying $R$ from 5 to 20 , is $6 \mathrm{~W}$, and when $\tau_{1}=60 \mu \mathrm{s}$, the corresponding output power variation $\Delta$ is $26 \mathrm{~W}$, i.e., the output power is slightly affected by the load $R$.

The experimental results of total efficiency $\left(U_{\mathrm{DC}}\right.$-load) versus the energy injection period $\tau_{1}$ are shown in Figure 16. It can be seen from Figure 16 that when $\tau_{1}=45 \mu \mathrm{s}, R=15 \Omega$, the output is the lowest, which is $84.8 \%$, and when $\tau_{1}=40 \mu \mathrm{s}, R=5 \Omega$, the output is the lowest, which is $80.9 \%$. The results of Figure 16 show that energy injection time has little effect on efficiency. 


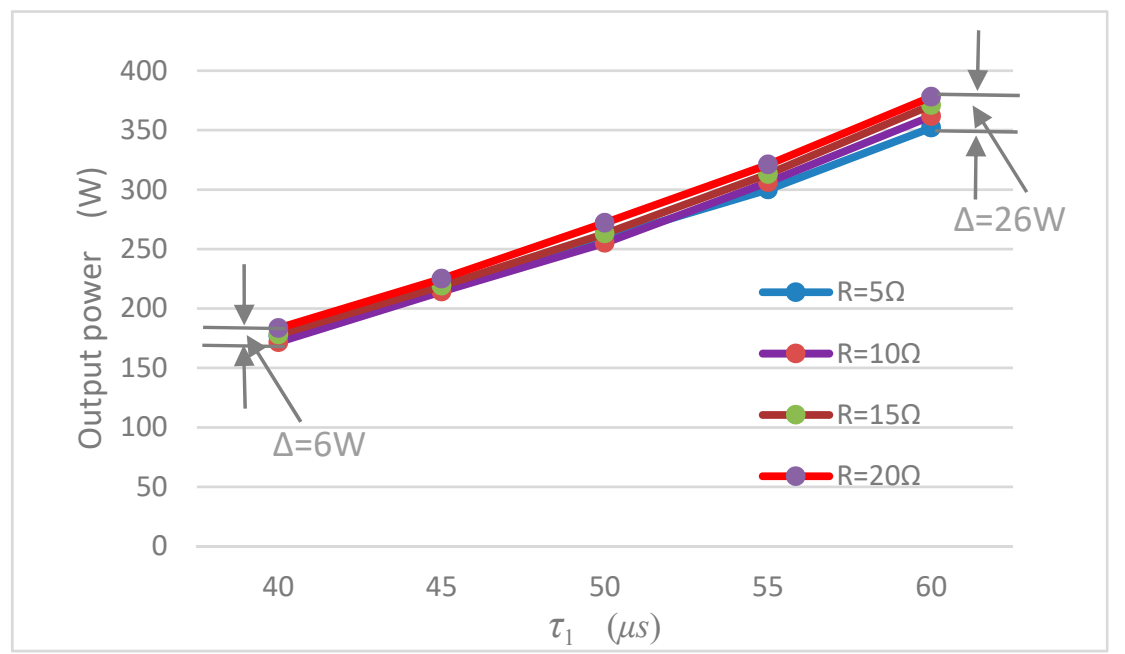

Figure 15. Output power versus the energy injection period $\tau_{1}$ under condition of $U_{\mathrm{DC}}=300 \mathrm{~V}$ and $k$ $=0.2$.

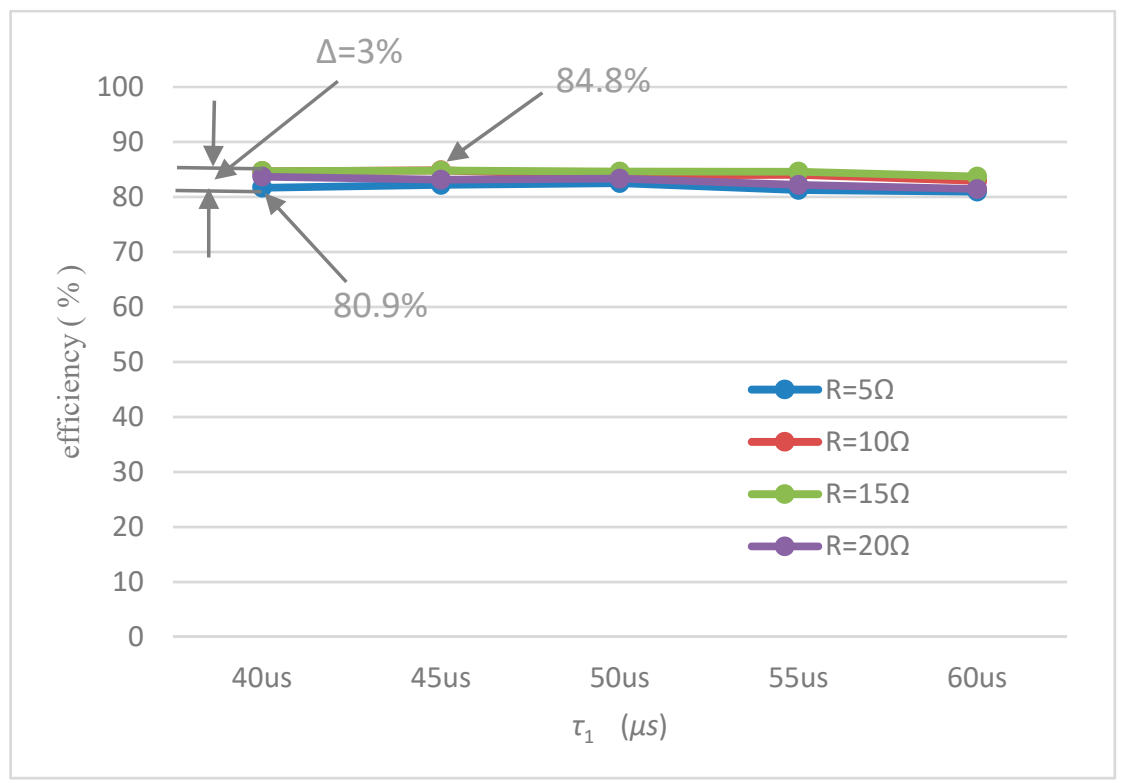

Figure 16. Total efficiency ( $U_{\mathrm{DC}}$-load) versus the energy injection period $\tau_{1}$ under condition of $U_{\mathrm{DC}}=300 \mathrm{~V}$ and $k=0.2$.

\subsection{Soft Switching}

The driving voltage $u_{\mathrm{g} 1}$, voltage drop $u_{\mathrm{ds} 1}$ of $\mathrm{S}_{1}$ and $i_{\mathrm{p}}$ are shown in Figure 17. In Figure $17, u_{\mathrm{g} 1}$ changes from low lever to high lever in time margin $T_{\mathrm{m} 1}$ to turn on $\mathrm{S}_{1}$. In this time margin, $u_{\mathrm{ds} 1}$ is zero, therefore, $\mathrm{S}_{1}$ is turned on under ZVS condition. Similarly, $u_{\mathrm{g} 1}$ changes from high to low level in time margin $T_{\mathrm{m} 2}$ to turn off $\mathrm{S}_{1}$, and in $T_{\mathrm{m} 2}, u_{\mathrm{ds} 1}$ is zero too. Therefore, $\mathrm{S}_{1}$ is turned off under ZVS condition. These results show that the switching operation of the IIEIFR converter does not need to be carried out at the current zero-crossing point but in a certain time slot to achieve soft switching condition. This feature reduces the complexity and difficulty of the control strategy. 


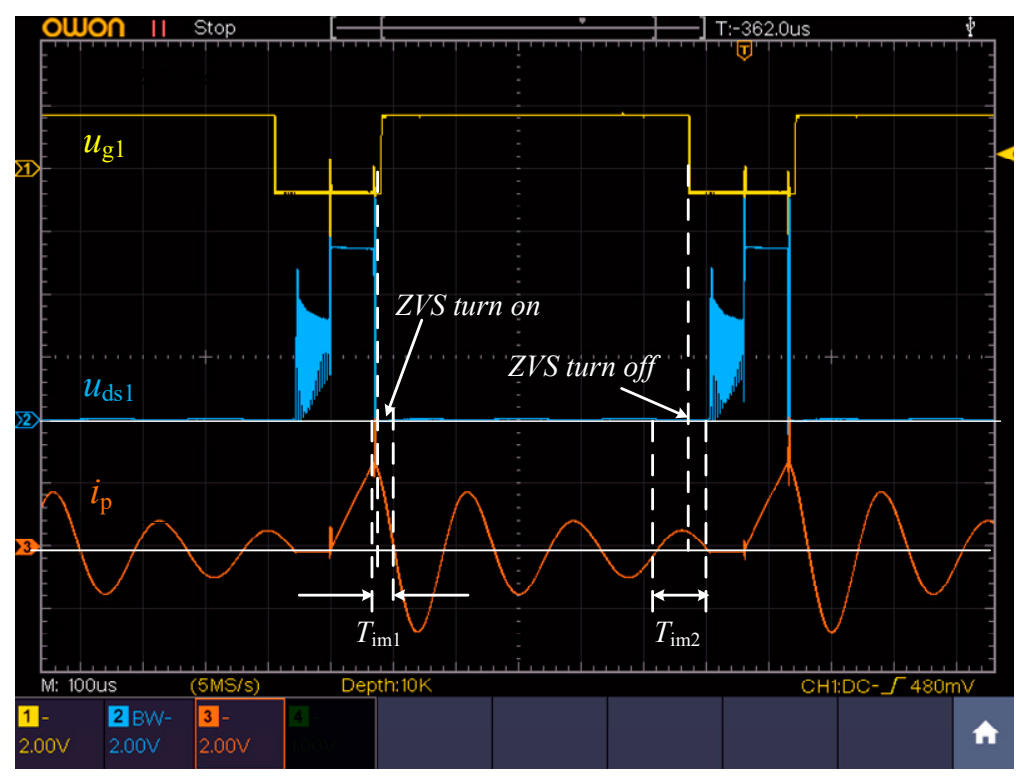

Figure 17. Experimental results of soft switching condition of IIEIFR converter.

\subsection{Power and Efficiency}

The experimental results of the relationship between the efficiency and coupling coefficient $k$ are shown in Table 4. In Table $4, k$ is represented by air gap, and the relationship of air gap and $k$ is shown in Figure 9. In the experiment, power analyzer (Yokogawa-WT300) was used to collect efficiency data. Considering that coil copper resistance, core loss and other factors will affect the efficiency of the magneto-electric system [34], and the experiment is to investigate the performance of the IIEIFR converter, it is necessary to eliminate the influence of the magneto-electric system in this paper. In Table $4, \mathrm{P}_{\text {in }}$ is the input power of the converter, $\mathrm{P}_{\mathrm{op}}$ is the output power of the converter (measured at the input side of the primary coil), $\mathrm{P}_{\mathrm{os}}$ is the output power of the magneto-electric system (measured at the load). $\eta_{\mathrm{p}}$ is the converter efficiency which is obtained by dividing $\mathrm{P}_{\mathrm{op}}$ by $\mathrm{P}_{\mathrm{in}}$. Obviously, this is the efficiency after removing the influence of the magneto-electric system. $\eta_{s}$ is the total efficiency, which is obtained by dividing $P_{\text {os }}$ by $P_{\text {in }}$, which includes the effect of magneto-electric system.

Table 4. Output power versus coupling coefficients.

\begin{tabular}{ccccccccc}
\hline Air Gap (cm) & $\mathbf{5}$ & $\mathbf{6}$ & $\mathbf{7}$ & $\mathbf{8}$ & $\mathbf{9}$ & $\mathbf{1 0}$ & $\mathbf{1 2}$ & $\mathbf{1 5}$ \\
\hline $\mathrm{P}_{\text {in }}(\mathrm{W})$ & 350 & 350 & 350 & 350 & 350 & 350 & 350 & 350 \\
$\mathrm{P}_{\mathrm{op}}(\mathrm{W})$ & 342.7 & 343.7 & 341.8 & 343.3 & 346.1 & 342.8 & 339.9 & 338.94 \\
$\mathrm{P}_{\mathrm{Oo}}(\mathrm{W})$ & 309.6 & 303.1 & 302.8 & 301.2 & 294.6 & 291.9 & 287.2 & 281.1 \\
$\eta_{\mathrm{p}}(\%)$ & 97.94 & 98.09 & 97.76 & 98.13 & 98.79 & 98.03 & 97.04 & 96.84 \\
$\eta_{\mathrm{s}}(\%)$ & 88.46 & 86.64 & 86.43 & 85.99 & 84.03 & 83.4 & 82.06 & 80.31 \\
\hline
\end{tabular}

As the air gap changes from $5 \mathrm{~cm}$ to $15 \mathrm{~cm}$, the converter efficiency, $\eta_{\mathrm{p}}$, is kept above $96.84 \%$, and the highest is $98.79 \%$ in the air gap of $9 \mathrm{~cm}$. This result confirms the high efficiency characteristic of the IIEIFR converter, and the high efficiency may be attributed to the soft switching operation, lower energy frequency than the resonance frequency and no power backflow to the source. In addition, this result means that the efficiency of the IIEIFR converter is slightly affected by the air gap (coupling coefficient).

The total efficiency $\eta_{\mathrm{s}}$ is less than the converter efficiency $\eta_{\mathrm{p}}$, when the air gap is $5 \mathrm{~cm}, \eta_{\mathrm{s}}$ is $88.46 \%$ and when air gap is $15 \mathrm{~cm}, \eta_{\mathrm{s}}$ is $80.31 \%$. Since the focus of this paper is on the research of IIEIFR converter, not to optimize the system, therefore, the magneto-electric system used in this experiment is not optimal. The efficiency of the system may be improved by using pads with a higher quality factor, for example, using pads with a quality factor higher than 500 [32]. In addition, the results also show 
that the total efficiency of the system decreases with the increase of the air gap, and that is due to the decrease of the efficiency of the magneto-electric system with the air gap.

\section{Conclusions}

A prototype of IPT converter based on IIEIFR control strategy was built to drive the IPT system in a wide air-gap range. Both simulations and experiments verify that the IIEIFR system can decouple the converter from the resonant network, and the power can be controlled independently by the energy injection period. The experimental results show that under the conditions of $U_{\mathrm{DC}}=300 \mathrm{~V}, k=0.2$ and $R=10 \Omega$, the output power can be controlled nearly linearly by the energy injection period in the range of 40-60 $\mu \mathrm{s}$, and the output power changed from $181 \mathrm{~W}$ to $379 \mathrm{~W}$. Since only the inductance is involved in the energy injection process, other parameters of the system have slight influences on the power control. It is verified by the experiment results that the load and coupling coefficient have slight influence on the power control.

In the tested air-gap range, the converter efficiency is maintained above $96.84 \%$, with a maximum of $98.79 \%$, which shows the high efficiency characteristic of the IIEIFR converter. The total efficiency will be affected by the performance of the magneto-electric system. Within the test range, the total efficiency decreases from $88.46 \%$ to $80.31 \%$ with the increase of the air gap.

The presented control strategy has two time margins for state transitions under ZVS conditions, which can reduce the control difficulty of the circuit. Simulations and experiments show that when the resonant frequency is $6.8 \mathrm{kHz}$, the switches in the prototype have time margins of $28.5 \mu \mathrm{s}$ and $73.7 \mu \mathrm{s}$ for turning on and off, respectively.

Author Contributions: Conceptualization, L.C.; methodology, L.C.; software, J.H.; validation, L.C., J.H. and Z.L.; formal analysis, W.C., J.H. and M.G.; investigation, L.C., J.H. and Z.L.; resources, W.C. and M.G.; data curation, L.C., J.H. and M.G.; writing—original draft preparation, L.C.; writing—review and editing, M.G.; visualization, M.G.; supervision, W.C.; project administration, W.C.; funding acquisition, W.C.

Funding: This research was funded by National Natural Science Foundation of China (NSFC), grant number 51777177; NSFC grant number 51707168; Key Projects of Fujian Collaborative Innovation Center for R\&D of Coach and Special Vehicle, grant number 2016AYF002.

Conflicts of Interest: The authors declare no conflict of interest.

\section{References}

1. Kim, C.G.; Seo, D.H.; You, J.S.; Park, J.H.; Cho, B.H. Design of a Contactless Battery Charger for Cellular Phone. IEEE Trans. Ind. Electron. 2001, 48, 1238-1247. [CrossRef]

2. Lu, Y.; Ma, D.B. Wireless Power Transfer System Architectures for Portable or Implantable Applications. Energies 2016, 9, 1087. [CrossRef]

3. Wu, H.H.; Gilchrist, A.; Sealy, K.D.; Bronson, D. A High Efficiency $5 \mathrm{~kW}$ Inductive Charger for EVs Using Dual Side Control. IEEE Trans. Ind. Inform. 2012, 8, 585-595. [CrossRef]

4. García, X.T.; Vázquez, J.; Roncero-Sánchez, P. Design, Implementation Issues and Performance of an Inductive Power Transfer System for Electric Vehicle Chargers with Series-series Compensation. IET Power Electron. 2015, 8, 1920-1930. [CrossRef]

5. Jiang, C.; Chau, K.T.; Liu, C.; Lee, C.H.T. An Overview of Resonant Circuits for Wireless Power Transfer. Energies 2017, 10, 894. [CrossRef]

6. Ibrahim, M.; Pichon, L.; Bernard, L.; Razek, A.; Houivet, J.; Cayol, O. Advanced Modeling of a 2-kw Series-series Resonating Inductive Charger for Real Electric Vehicle. IEEE Trans. Veh. Technol. 2015, 64, 421-430. [CrossRef]

7. Hwang, K.; Cho, J.; Kim, D.; Park, J.; Kwon, J.H.; Kwak, S.I.; Park, H.H.; Ahn, S. An Autonomous Coil Alignment System for the Dynamic Wireless Charging of Electric Vehicles to Minimize Lateral Misalignment. Energies 2017, 10, 315. [CrossRef]

8. Villa, J.L.; Sallan, J.; Sanz Osorio, J.F.; Llombart, A. High-misalignment tolerant compensation topology for icpt systems. IEEE Trans. Ind. Electron. 2012, 59, 945-951. [CrossRef] 
9. Kan, T.; Nguyen, T.D.; White, J.C.; Malhan, R.K.; Mi, C.C. A new integration method for an electric vehicle wireless charging system using lcc compensation topology: Analysis and design. IEEE Trans. Power Electron. 2017, 32, 1638-1650. [CrossRef]

10. Sohn, Y.H.; Choi, B.H.; Lee, E.S.; Lim, G.C.; Cho, G.H.; Rim, C.T. General unified analyses of two-capacitor inductive power transfer systems: Equivalence of current-source SS and SP compensations. IEEE Trans. Power Electron. 2015, 30, 6030-6045. [CrossRef]

11. Moradewicz, A.J.; Kazmierkowski, M.P. Contactless energy transfer system with FPGA-controlled resonant converter. IEEE Trans. Ind. Electron. 2010, 57, 3181-3190. [CrossRef]

12. Jesús, S.; Villa, J.L.; Andrés, L.; José, F.S. Optimal design of ICPT systems applied to electric vehicle battery charge. IEEE Trans. Ind. Electron. 2009, 56, 2140-2149. [CrossRef]

13. Keeling, N.A.; Covic, G.A.; Boys, J.T. A unity power factor IPT pick-up for high power applications. IEEE Trans. Ind. Electron. 2010, 57, 744-751. [CrossRef]

14. Kim, J.H.; Lee, I.O.; Moon, G.W. Analysis and design of a hybrid-type converter for optimal conversion efficiency in electric vehicle chargers. IEEE Trans. Ind. Electron. 2017, 64, 2789-2800. [CrossRef]

15. Choi, S.Y.; Gu, B.W.; Jeong, S.Y.; Rim, C.T. Advances in wireless power transfer systems for roadway-powered electric vehicles. IEEE J. Emerg. Sel. Top. Power Electron. 2014, 3, 18-36. [CrossRef]

16. Zheng, C.; Ma, H.; Lai, J.S.; Zhang, L. Design Considerations to Reduce Gap Variation and Misalignment Effects for the Inductive Power Transfer System. IEEE Trans. Power Electron. 2015, 30, 6108-6119. [CrossRef]

17. Cirimele, V.; Diana, M.; Freschi, F.; Mitolo, M. Inductive power transfer for automotive applications: State-of-the-art and future trends. IEEE Trans. Ind. Appl. 2018, 54, 4069-4079. [CrossRef]

18. Mi, C.C.; Buja, G.; Choi, S.Y.; Rim, C.T. Modern advances in wireless power transfer systems for roadway powered electric vehicles. IEEE Trans. Ind. Electron. 2016, 63, 6533-6545. [CrossRef]

19. Matysik, J.T. The Current and Voltage Phase Shift Regulation in Resonant Converters with Integration Control. IEEE Trans. Ind. Electron. 2007, 54, 1240-1242. [CrossRef]

20. Gati, E.; Kampitsis, G.; Manias, S. Variable Frequency Controller for Inductive Power Transfer in Dynamic Conditions. IEEE Trans. Power Electron. 2017, 32, 1684-1696. [CrossRef]

21. Matysik, J.T. A New Method of Integration Control with Instantaneous Current Monitoring for Class D Series-Resonant Converter. IEEE Trans. Ind. Electron. 2006, 53, 1564-1576. [CrossRef]

22. Moghaddami, M.; Sundararajan, A.; Sarwat, A.I. A Power-Frequency Controller with Resonance Frequency Tracking Capability for Inductive Power Transfer Systems. IEEE Trans. Ind. Appl. 2018, 54, 1773-1783. [CrossRef]

23. Miller, J.M.; Onar, O.C.; Chinthavali, M. Primary-side power flow control of wireless power transfer for electric vehicle charging. IEEE J. Emerg. Sel. Top. Power Electron. 2015, 3, 147-162. [CrossRef]

24. Madawala, U.K.; Neath, M.; Thrimawithana, D.J. A power-frequency controller for bidirectional inductive power transfer systems. IEEE Trans. Ind. Electron. 2013, 60, 310-317. [CrossRef]

25. Berger, A.; Agostinelli, M.; Vesti, S.; Oliver, J.A.; Cobos, J.A.; Huemer, M. A wireless charging system applying phase-shift and amplitude control to maximize efficiency and extractable power. IEEE Trans. Power Electron. 2015, 30, 6338-6348. [CrossRef]

26. Dede, E.J. Improving the Efficiency of IGBT Series-resonant Inverters using Pulse Density Modulation. IEEE Trans. Ind. Electron. 2011, 58, 979-987. [CrossRef]

27. Fujita, H.; Akagi, H. Pulse-density-modulated Power Control of a 4 kw, $450 \mathrm{kHz}$ Voltage-source Inverter for Induction Melting Applications. IEEE Trans. Ind. Appl. 1996, 32, 279-286. [CrossRef]

28. Li, H.L.; Hu, A.P.; Covic, G.A. Development of a Discrete Energy Injection Inverter for Contactless Power Transfer. In Proceedings of the 2008 3rd IEEE Conference on Industrial Electronics and Applications, Singapore, 3-5 June 2008; pp. 1757-1761. [CrossRef]

29. Li, H.L.; Hu, A.P.; Covic, G.A. A Direct AC-AC Converter for Inductive Power-Transfer Systems. IEEE Trans. Power Electron. 2012, 27, 661-668. [CrossRef]

30. Chen, L.; Hong, J.; Guan, M.; Wu, W.; Chen, W. A Power Converter Decoupled from the Resonant Network for Wireless Inductive Coupling Power Transfer. Energies 2019, 12, 1192. [CrossRef]

31. Wang, C.S.; Covic, G.A.; Stielau, O.H. Power transfer capability and bifurcation phenomena of loosely coupled inductive power transfer systems. IEEE Trans. Ind. Electron. 2004, 51, 148-157. [CrossRef]

32. Kamineni, A.; Covic, G.A.; Boys, J.T. Self-Tuning Power Supply for Inductive Charging. IEEE Trans. Power Electron. 2017, 32, 3467-3479. [CrossRef] 
33. Esteve, V.; Jordan, J.; Sanchis-Kilders, E.; Dede, E.; Maset, E.; Ejea, J. Enhanced pulse-density-modulated power control for high frequency induction heating inverters. IEEE Trans. Ind. Electron. 2015, 62, 6905-6914. [CrossRef]

34. Lin, F.Y.; Covic, G.A.; Boys, J.T. Evaluation of Magnetic Pad Sizes and Topologies for Electric Vehicle Charging. IEEE Trans. Power Electron. 2015, 30, 6391-6407. [CrossRef] 